\title{
Optimal bid model for construction contracts
}

\author{
Renard Y.J. Siew \\ School of Civil and Environmental Engineering, \\ UNSW, \\ 2052, Sydney \\ Email: rensiew10@gmail.com
}

\begin{abstract}
Construction clients are increasingly calling for bids that require contractors to submit both bid price and highlight sustainability attributes. Contractors are faced with the problem of deciding which combination of bid price and sustainability attributes to submit. An important consideration is the cost of sustainability attributes to the client. This varies between contracts and types of projects. This paper proposes the use of a sustainability unit value which the client can use as a basis for determining the contractor's total combined bid. This kind of procurement method is traditionally known as the $\mathrm{A}+\mathrm{B}$ method. To illustrate the mechanism of price-sustainability attribute bi-parameter procurement, a total combined ISO-map is developed. The contractor's price-sustainability performance curve is then incorporated into the map to determine the contractor's optimal bid parameters: tender price and sustainability performance. A mathematical optimisation bid model is developed for calculating the optimal bid parameters.
\end{abstract}

Keywords: optimal bid value; price; sustainability attributes; construction contracts.

Reference to this paper should be made as follows: Siew, R.Y.J. (2017) 'Optimal bid model for construction contracts', Int. J. Sustainable Real Estate and Construction Economics, Vol. 1, No. 1, pp.51-66.

Biographical notes: Renard Siew is a Postdoctoral Teaching Fellow at UNSW. His interest lies in sustainability/ integrated reporting and sustainable construction of buildings/infrastructure. With the support of the Australian Postgraduate Award (APA) Scholarship, he completed his $\mathrm{PhD}$ focusing on the effectiveness of sustainability rating tools. He also completed his Postgraduate Certificate in Sustainable Value Chains from Cambridge University. He was the recipient of the Yayasan Sime Darby Scholarship and ARG Hermes Scholarship. He serves as an industry working group member with the Sustainability Accounting Standards Board (SASB).

\section{Introduction}

Although there are many existing contracting models but a majority of construction contracts are procured under a low bid system, that is, tender price is seen as the primary criterion by the client in awarding the contract. Another commonly discussed criterion in contracts is construction time. Shen et al. (1999, p.204) argue that the "early completion of a project can have a profound contribution to the return of their investment, and the delayed delivery of a project will normally cause loss of business opportunities and 
potential profits, or, for public projects create social problems." In an attempt to reduce contract duration, clients have turned to fast track contracting methods. One such example is the development of innovative procurement procedures which include bidding on cost and time (Herbsman et al., 1995). For this bidding procedure, a certain monetary value is given to each unit of time and this time value is incorporated with the bid price in evaluating the contractor's total combined bid (TCB). According to Herbsman et al. (1995) bidding on both cost and time has been successfully applied in US state highway agencies.

In this era, sustainability attributes in a built environment that help minimise consumption of energy, materials and water as well as improve the liveability of residents are becoming increasingly important to all stakeholders of a project (One Planet Living, 2007). This is given the increasing awareness of the concept on sustainable construction (Kibert, 1994; Siew, 2014a) defined as: the creation of a healthy built environment using resource-efficient, ecologically-based principles. Projects that incorporate sustainability attributes such as building projects with certified 'green' ratings (Siew et al., 2013) have many benefits including better environmental and social impacts; enhanced company reputation; and potential cost savings as a result of more energy efficient features in buildings (GBCA, 2013). It was reported that on average, Green Star certified buildings produce $62 \%$ fewer greenhouse gas emissions, use $66 \%$ less electricity than Australian buildings and $51 \%$ less potable water than average buildings. Miller et al. (2008) find that the results are promising for investment in sustainable real estate when comparing between LEED certified and non-LEED certified (see Siew et al., 2013) office property in the USA.

Given these benefits, instead of determining the most competitive bid price and the specified time of completion in tender documents, contractors would now need to look more closely at sustainability attributes of projects. Clients, on the other hand, have to determine which contractor to award the contract to considering both price and sustainability attributes. To increase the chances of winning a construction contract, the contractor needs to relate the bid strategy to the relative importance placed by the client on price and sustainability attributes. Existing contracting models are focused on two criteria namely price and time with little to no consideration for sustainability attributes (Shen et al., 1999; Gupta, 2011; Hosseinian and Carmichael, 2012). This paper addresses the current gap in research by offering an optimal price-sustainability attribute model based on the client's unit sustainability attribute value (SAV). The thinking behind this framework is original and has not been addressed in prior literature.

\section{Literature review}

The literature review is motivated by the aim to have a comprehensive view on the subject of contracting methods and sustainability attributes. Specifically, the objectives of the review are to:

- investigate whether contracting methods have considered sustainability attributes

- identify relevant tools in the market that measure sustainability attributes or performance. 
Abudayyeh et al. (2007) highlight that the three innovative contracting methods used by the Federal Highway Administration (FHwA) are design-build, cost plus time and warranty. They made a further contribution to the literature on contracting by proposing a methodology that helps public clients prequalify and select contractors within the context of these three delivery methods. Three of these mainstream contracting methods are discussed in turn.

Table 1 Literature review on contracting methods

\begin{tabular}{lcc}
\hline No. & Contracting methods & Authors \\
\hline 1 & Cost plus time & Lambropoulos (2007), Akintoye et al. (1998), Gordon (1994), \\
& & Berends (2000), Kwon et al. (2010), Chan et al. (2001), \\
& & Akintoye et al. (1994) and Hale et al. (2009) \\
2 & Design and build & Songer and Molenaar (1996), Chan and Yu (2005) and \\
& & Gransberg and Senadheera (1999) \\
3 & Warranty & Erevelles (1993), Thompson et al. (2002), Singh et al. (2007), \\
& & Bayraktar et al. (2004) and Harrington et al. (1984) \\
\hline
\end{tabular}

\section{Design-build}

Design and build is a popular contracting method where the contractor completes the design started by the designers of the employer. The initial design can be as little as performance specifications up to a fully developed set of drawings. This method of contracting is cost-effective since the price is fixed provided there are no further variations such as changes to the employer's requirements. Ndekugri and Turner (1994) report on a survey of contractors, designers and building clients regarding design and build issues. Based on the results of the survey, they find that the use of design and build is on the rise with many clients perceiving it as being value for money and lesser disputes compared to other procurement methods.

\section{Cost plus time}

This contracting method, also known as the $\mathrm{A}+\mathrm{B}$ bidding involves time, with an associated cost. The contractor is selected based on the lowest bidder selected from the monetary combination of contract bid items (A) and the time (B) needed to complete the project. $\mathrm{A}+\mathrm{B}$ bidding is typically used to motivate the contractor through contract incentives to minimise the delivery time. This is intended to encourage contractors to more actively manage their work schedule construction management processes to reduce construction duration and reduce any inconvenience to the public. Rosenfield and Geltner (1991) discuss two problems associated with cost-plus time contracts namely the financial costs of an earlier construction start through the use of 'fast-tracked' designbuild cycle and the counterproductive effects of 'adverse selection' of competing companies which must occur through the use of cost-plus time contracts. An example of this contracting method in highway projects is given in equation (2). 


\section{Warranty}

A warranty is a term collateral to the main purpose of the contract. The Canadian Construction Documents Committee (CCDC, 1998) claims that a construction warranty fulfils the following criteria:

- $\quad$ protects the client against defects or failures within the warranty period

- provides a remedy to the client for non-conformance with the contract discovered prior to or after 'substantial performance of the work'

- gives the client recourse against other parties (i.e., manufacturers, subcontractors, suppliers) which may not be in a direct contractual relationship with the client

- defines the responsibilities of all parties regarding the coverage of the warranty.

The breach of warranty entitles a party to claim damages. Typically, the client receives nothing from the warranty contract if the good works satisfactorily. If the good shows any defect, the client gets coverage promised in the contract. Warranties include replacement or repair of defective products, price refunds and reimbursement for consequential damages (Emons, 1989).

While much has been written on different contracting methods, yet, the search reveals that the literature on 'green' contracting methods is still relatively immature. Cui and Zhu (2011) report on green contracting practice for delivering highway projects in the USA based on a survey with 39 state departments of transportation. They find that there is still a substantial lack of consistent methodology, terminology and processes for implementing 'green' contracting. Varnäs et al. (2009) claim that environmental criteria in tender evaluation are less common and seldom affect the award decisions. Guggemos and Horvath (2006) propose the Construction Environmental Decision-Support Tool to allow designers and practitioners to quantify energy use, emissions and waste generation due to the construction phase of commercial buildings. Palmujoki et al. (2010) highlight that although 'green' criteria are often included in calls for tenders, it is not necessarily that they are included in the final contract clauses. They further argue that opportunities for incorporating 'green' aspects into contracts is important as they help ensure that 'green' criteria are fulfilled by the purchased products or services during the contract period. Given that very few studies have attempted to incorporate sustainability attributes into bid evaluation, this paper aims to fill the research gap accordingly.

\section{Sustainability reporting tools}

From the literature, it was found that there are many sustainability reporting tools (SRTs) available in the market to gauge the level of sustainability of buildings/infrastructure (Cole, 1999; Crawley and Aho, 1999; Siew et al., 2013; Siew, 2014a, 2014b). The use of SRTs demonstrates the commitment of building owners and operators towards their environmental responsibility and permits staying ahead of future regulations. Cole (1999) argues that the definition of building performance varies according the different interest of parties involved in building development. For example, a building owner would 
perceive the performance of a building from a cost efficiency perspective whereas occupants will be more concerned about indoor air quality, comfort, health and safety issues. An ideal environmental building assessment will include all the requirements of different parties involved.

A few of these mainstream tools include BREEAM, Green Star and LEED are detailed by Siew et al., 2013). An understanding of the nature of SRTs is important as they are incorporated into the contracting model proposed in this paper. SRTs publish ratings of specific projects to reward sustainability outcomes and encourage moving beyond standard practice. As an example, building research establishment environmental assessment method (BREEAM), awards scores against ten criteria - management, health and wellbeing, energy, transport, water, materials, waste, land use and ecology, pollution and innovation - according to performance, and summed to produce an overall score. This score is then matched to a rating: pass, good, very good, excellent or outstanding (Siew et al., 2013) as given in Table 2.

Table 2 BREEAM rating

\begin{tabular}{lc}
\hline Rating & Score $(\%)$ \\
\hline Unclassified & $<30$ \\
Pass & $\geq 30$ \\
Good & $\geq 45$ \\
Very good & $\geq 55$ \\
Excellent & $\geq 70$ \\
Outstanding & $\geq 85$ \\
\hline
\end{tabular}

\section{SAV}

In this paper, sustainability attribute is related to expected monetary benefits in terms of a SAV. SAV represents the net value for embedding sustainable design features which consist of the following two components:

1 Sustainability rating (SR) which represents the sustainability performance of the project. For buildings, this could be the ratings used by one of the mainstream SRTs (Siew et al., 2013; Siew, 2014b) such as Green Star, BREEAM, LEED and CASBEE among others. This can be obtained from the SRT providers themselves or alternatively the project manager can conduct a self-assessment of the projects using the SRT.

2 A ratio of monetary benefits per increment in the level of sustainability rating. This data can be easily obtained from existing research reports capturing the benefits per increment in sustainability rating $(\mathrm{Ng}, 2013)$.

$\mathrm{SAV}$ is given in equation (1).

$$
S A V=S R \times \lambda
$$


where

$S A V$ sustainability attribute value

$S R \quad$ sustainability rating

$\lambda \quad \$$ sustainability rating.

\section{TCB}

Bidding on cost and time is typically the most popular method utilised for highway contracts (El-Rayes, 2001; Lambropoulos, 2007).

The successful bidder is the contractor who submits the lowest TCB according to the formula:

$$
T C B=E C C+(D R U C \times E P D)
$$

where

$T C B \quad$ total combined bid (\$)

$E C C$ estimated cost of construction

$D R U C$ daily road user cost

$E P D$ estimated project duration.

By applying (2), the contractor that submits the lowest TCB will be considered as having the highest level of competitiveness. TCB is written from the perspective of the client for awarding road contracts. To encompass a more generic construction contract where priceSAV bidding is used, the foregoing equation is rewritten as:

$$
T C B^{\prime}=p-S A V
$$

where

$T C B^{\prime} \quad$ total competitiveness bid

$p \quad$ contractor's tender price

$S A V \quad$ sustainability attribute value.

Assume that a contractor, denoted $\mathrm{ABC}$ is tendering for a construction contract where $\lambda=\$ 1,000 /$ rating. The contractor considers two bidding strategies: (1) bidding strategy $\mathrm{x}$; submit the tender comprising of a sustainability rating of 4 (SAV of $\$ 4,000)$ with a bid price of $\$ 100,000$ and (2) bidding strategy y: submit the tender comprising of a sustainability rating of 6 (SAV of $\$ 6,000$ ) with a bid price of $\$ 101,000$. By applying (3), it can be seen that $\mathrm{TCB}^{\prime}$ from strategies $\mathrm{x}$ and $\mathrm{y}$ are as follows:

$$
\begin{aligned}
& T C B^{\prime}(x)=\$ 100,000-\$ 4,000=\$ 96,000 \\
& T C B^{\prime}(y)=\$ 101,000-\$ 6,000=\$ 95,000
\end{aligned}
$$

In this scenario, strategy y has a better overall competitiveness value of $\$ 1000$ although it has a higher price bid. 


\section{TCB-ISO map}

In the previous example, where SAV of $\$ 4,000$ and $\$ 6,000$ is applied, by trading off between bid price and SAV, the contractor ABC could have other bidding strategies that would offer the same TCB of $\$ 95000$. For example, the contractor could have another bidding strategy z comprising of sustainability rating of 5 (SAV of $\$ 5,000)$ with a bid price of $\$ 100,000$. The TCB' for strategy $\mathrm{z}$ would be:

$$
T C B^{\prime}(z)=\$ 100,000-\$ 5,000=\$ 95,000
$$

In other words, the client would consider strategy y and $\mathrm{z}$ to have the same level of competitiveness. It depends on the contractor to decide which price-SAV combination to submit. The contractor would compare available options taking into consideration company practice, availability of resources and which strategy has a greater benefit before making the choices between strategy y and $\mathrm{z}$.

Looking at equation (3), there are infinite combinations of bid price and SAV that give the same TCB'. When the combinations are plotted on a price-SAV right-angled diagram, they form a linear line known as an ISO-line shown in Figure 1. The slope of the line depends on $\lambda$. As all points on this line give the same TCB' value, this line is referred to as the TCB' ISO-line. Each point on the the TCB' ISO-line represents a particular bidding strategy but has the same competitiveness value. In principle, these infinite points on the ISO-line suggest that a contractor have many bidding strategies offering the same $\mathrm{TCB}^{\prime}$. This ISO-line also provides an indication that there is a possibility that more than one contractor have the same level of competitiveness but with different tender price and contract time. With a specified $\lambda$, when different $\mathrm{TCB}^{\prime}$ values are given, a set of TCB' ISO-line can be plotted on a diagram forming a $\mathrm{TCB}^{\prime}$ map shown in Figure 1.

Figure 1 Contractor's overall competitiveness: TCB' ISO-line

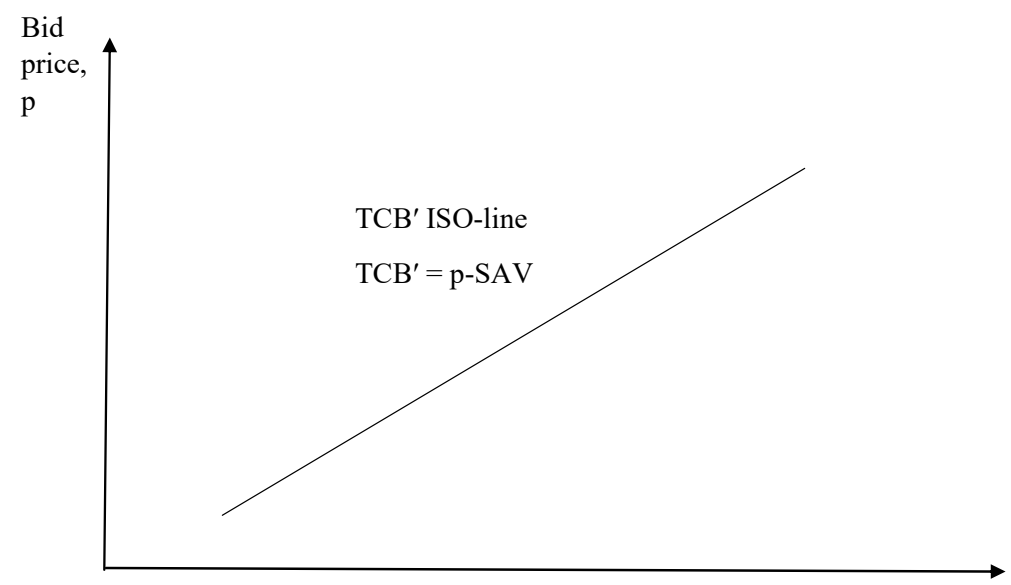


Figure 2 shows that there are two TCB' values: $\mathrm{TCB}^{\prime} 1$ and $\mathrm{TCB}^{\prime} 2$ from Contractors 1 and 2 . By applying $\lambda=1,000 /$ rating, the client would give the contract to contractor 2 with offers a rating 5 project with a bid price of $\$ 101,000$ giving a TCB $^{\prime}$ of $\$ 90,000$. Contractor 1 obtains a $\mathrm{TCB}^{\prime}$ of $\$ 99,000$ by offering a contract with a rating 1 project with a bid price of $\$ 100,000$. As the TCB' value represents the client's price-SAV evaluation on contractor's competitiveness, the contractor whose offer falls on the lowest TCB' line is the most competitive and will, therefore win the contract.

Figure 2 Contractor's overall competitiveness: TCB' ISO-map

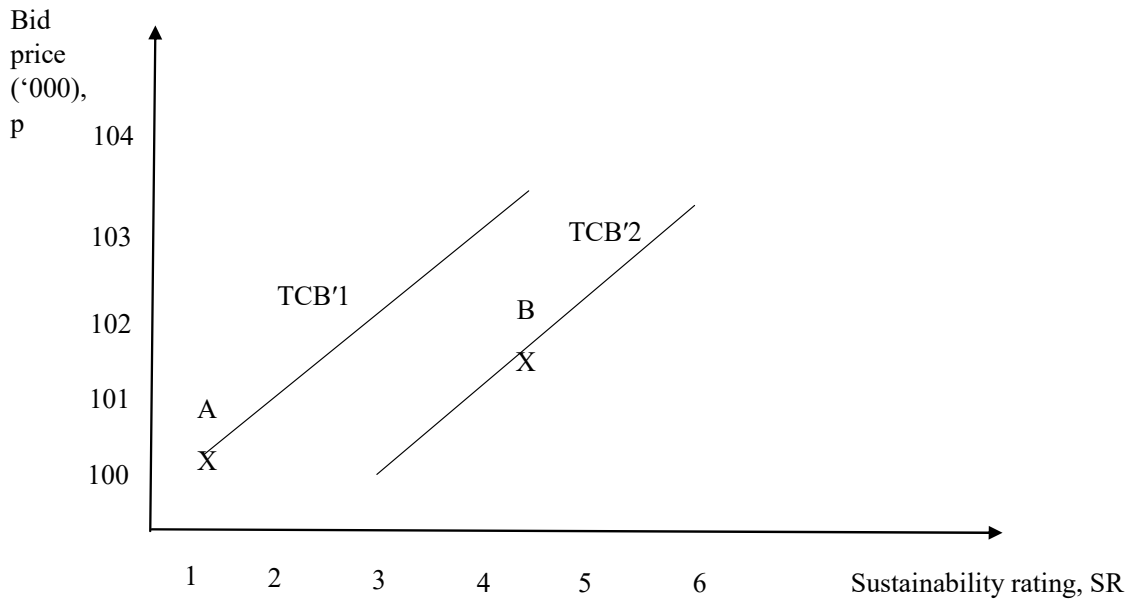

The client can construct the TCB' ISO-map by using a set of TCB' values and $\lambda$ as the slope. All anticipated contractor's bids can be plotted on the TCB' ISO-map. The client will then use the TCB' ISO-map to select contractors. The selected contractor will have the lowest TCB' ISO-map. As contractors are competing with each other, it is important for them to know where they sit on the TCB' ISO-map.

\section{Construction cost, tender price and construction time}

Literature pertaining to construction project scheduling shows that there is an optimum cost-time point for every construction contract. There is an interrelationship between construction cost and time and this can be expressed in a curve as shown in Figure 3. On this curve, the normal point represents the construction plan where construction cost is the lowest with a specific construction time. Variation in time from the normal point will result in a corresponding increase in construction cost. For example, to shorten the construction time will lead to an increase in construction cost as this would involve the use of multiple shifts, overtime work and other costly measures. The minimum time to which the construction of a project can be reduced in called 'crash point'. Normal points are where construction costs is the lowest and this differs from one contractor to another because of different construction techniques and skills.

A contractor's tender price for a contract is actually closely related to his construction cost and such a relation can be written in the following formula: 


$$
p=c(1+\alpha)
$$

where $p=$ tender price; $c=$ estimation of construction cost that has the relation with construction time; $\alpha=$ mark-up coefficient applied by the contractor as shown in Figure 3. Therefore, the contractor's tender price is also closely related to construction time, and such a relation can be denoted with the following equation:

$$
p=f(t)
$$

where $p=$ tender price, $t=$ construction time and $f$ represents a certain function relation between $\mathrm{p}$ and $\mathrm{t}$.

Figure 3 Interrelationship of construction cost and time

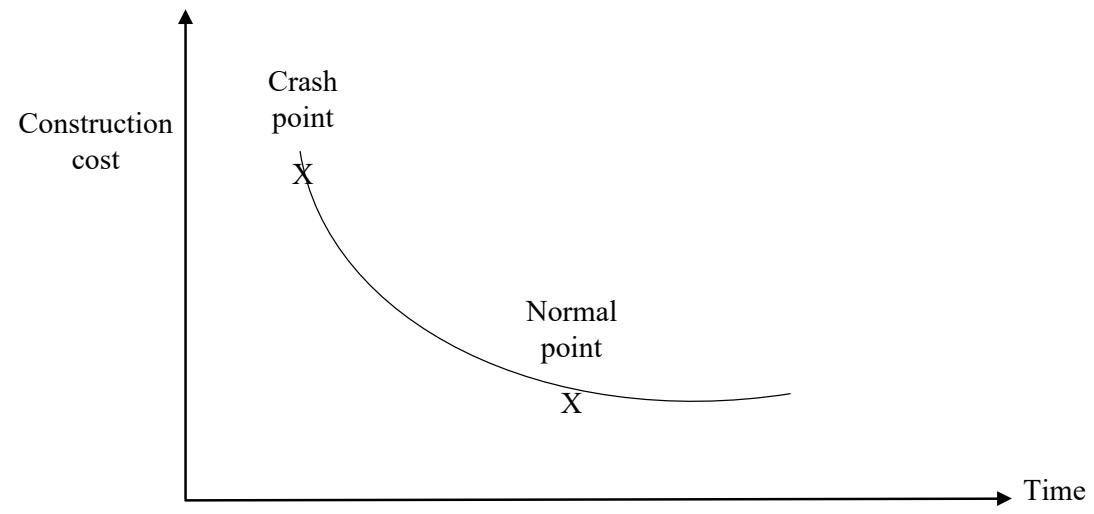

Figure 4 Interrelationship between construction cost and sustainability rating

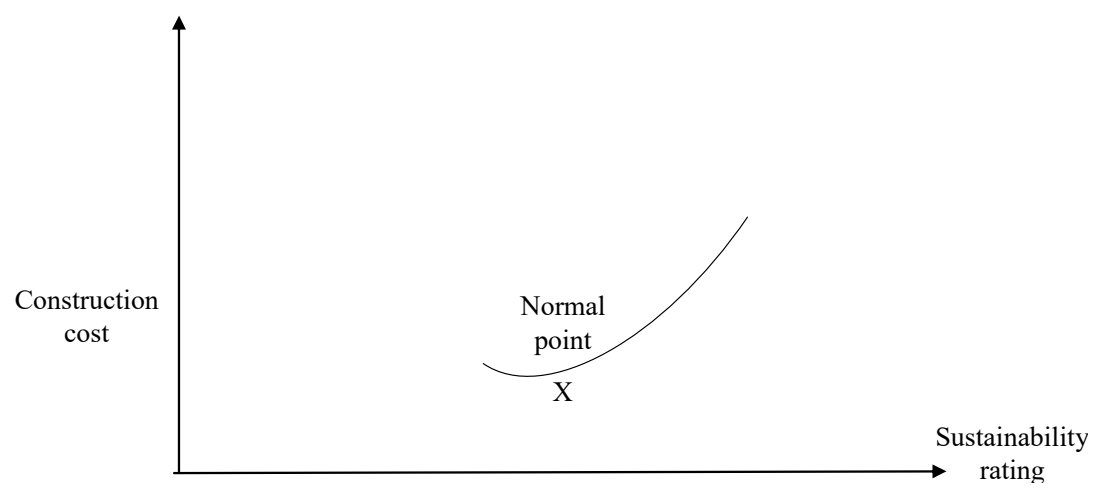

It is argued in this paper that the relationship between construction cost and sustainability rating can also be modelled after equation (5) similarly to the relationship between construction cost and time (see Figure 4). Variation in rating from the normal point will result in a corresponding increase in construction cost. Typically, if a building project is proposed at a certain sustainability rating, there will be government funding which reduces the overall cost of construction (USGBC, 2014; Siew, 2015). However, if the project owner wishes to increase the sustainability performance of the project above and 
beyond the minimum requirement to apply for funding this will naturally lead to an increase in construction cost.

\section{Impact of SAV on contractor's competitive tender plan}

In a situation where the client cares about the significance of sustainability rating, he will apply a preferred $\lambda$ and the sustainability rating of the project proposed by the contractor becomes more significant. The application of $\lambda$ enables the client to evaluate the contractor's overall competitiveness by considering the tender price and sustainability rating collectively. Such an application attracts contractors to propose a higher sustainability rating taking into account both the practice and business situation within their organisations and the impact of $\lambda$ to produce their most competitive TCB'.

The impact of $\lambda$ on the contractor's most competitive tender plan can be analysed as shown in Figure 5. Curve A1 represents a contractor's price-rating curve. Curve A2 is the sustainability rating value line (straight line) representing the client's rating value determined by $\lambda$. When the client evaluates the contractor's overall competitiveness, the client will calculate the contractor's total $\mathrm{TCB}^{\prime}$ by using the model introduced in equation (3). Curve A represents the contractor's TCB' values. Therefore, in applying the price-rating bi-parameter procurement approach, the $\mathrm{TCB}^{\prime}$ curve $\mathrm{A}$ becomes the contractor's competiveness curve and the lowest point on the $\mathrm{TCB}^{\prime}$ curve represents the most competitive bidding strategy given by point $\mathrm{a}_{0}$ in Figure 5 .

In Figure 5, if the contractor assumes that the client would only consider tender price, the most competitive bid would be at point $\mathrm{a}_{1}$ on the price-rating curve. However, in price-rating competition, the contractor needs to also factor in the client's application of SAV. This changes the game plan as the contractor would need to change his tender strategy from $a_{1}$ to $a_{2}$ in order to offer his most competitive strategy. Even though $a_{1}$ appears to initially have the lowest bid price for a given sustainability rating but after factoring in the SAV, the client would find $\mathrm{a}_{2}$ more competitive because of the potential savings generated from having better sustainability performance. This shows that the value of sustainability rating has a major influence on the contractor's tendering strategy.

Figure 5 Impact of SAV on contractor's competitive tender plan.

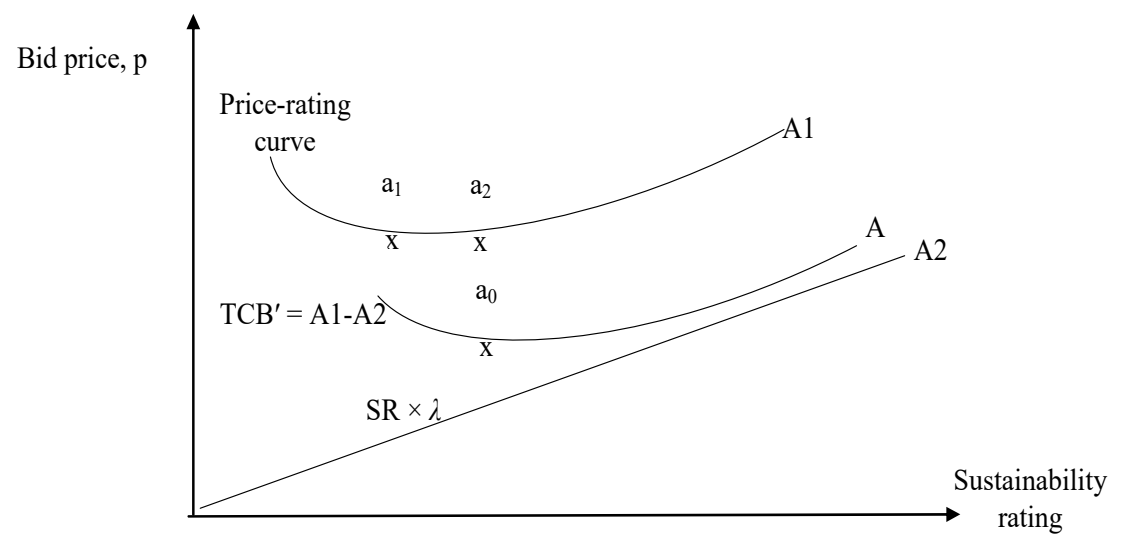


Under the traditional low bid system, the client does not normally consider the SAV measure at the time of awarding the contract, and contractors do not usually consider about the sustainability rating of projects from that defined in the contract. However, under the new price-rating contractual arrangement, the client is in effect increasingly willing to reimburse the contractor for higher sustainability rating with a specified rate. This motivates the contractor to propose projects with higher sustainability rating and submit a more competitive tender considering the minimum TCB value from the client's perspective.

\section{Contractor's optimisation bid model}

The impact of SAV on the contractor's most competitive tender can be analysed on the TCB ISO-map introduced in the earlier section. Introducing the contractor's price-rating curve to the TCB' ISO-map the following graphs can be obtained as shown in Figure 6.

Figure 6 Optimal bid-point on the TCB' ISO-map

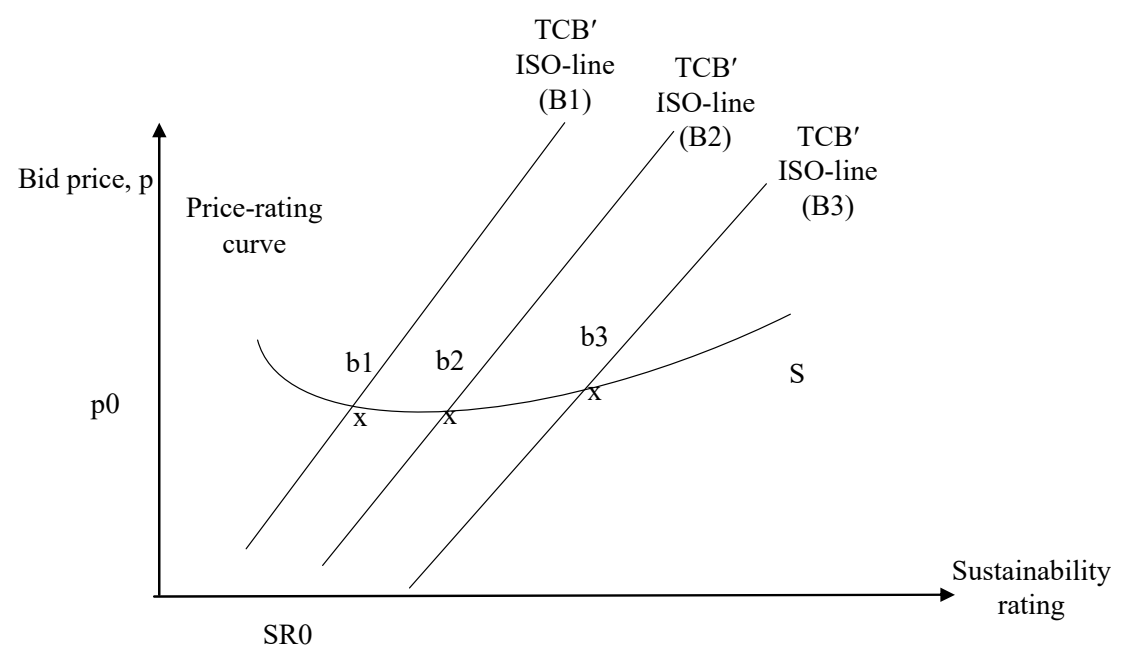

In Figure 6, $\mathrm{S}$ is the contractor's price-rating curve. Point b2, the lowest point of on the curve that falls on the TCB' ISO-line B2 would be the contractor's most competitive tender ignoring the value of sustainability rating imposed by the client. By submitting this tender, the contractor's TCB' value assessed by the client would be TCB' (B2). The contractor can get another bid strategy at point b2, by following the TCB' (B2) ISO-line.

By examining other points on the curve $\mathrm{S}$ in Figure 6, the contractor will be able to locate another point $\mathrm{b} 1$ where the curve $\mathrm{S}$ in in tangent with a particular TCB' ISO-line (TCB' $\mathrm{B} 1$ ). It can be observed that the $\mathrm{TCB}^{\prime} \mathrm{B} 1$ is the lowest position among all possible ISO-lines crossing curve $\mathrm{S}$. This means that the contractor's $\mathrm{TCB}^{\prime}$ value at point $b 1$, is the minimum TCB that the contractor can offer, in which price $p_{0}$ and sustainability rating $S R_{0}$ are offered.

The actual value of $\mathrm{p}_{0}$ and $\mathrm{SR}_{0}$ can be further analysed by developing a mathematical model. By referring to the shape of the price-rating curve $S$ given in Figures 5 and 6 , the 
relationship between tender price and sustainability rating is assumed to follow a quadratic equation which can be written as:

$$
p=a+b S R+c S R^{2}
$$

where $p=$ tender price, $S R=$ sustainability rating; and $a, b$ and $c$ are constants. Equation (5) is the quantitative form of curve S. Hence, the slope of the price-rating curve is given as:

$$
p^{\prime}(S R)=b+2 c S R
$$

At point b1, the slope of the price-rating curve is rewritten as:

$$
p^{\prime}\left(S R_{0}\right)=b+2 c S R_{0}
$$

On the other hand, the tangent point also falls on the TCB' ISO-line (B1). By referring to 3 , the TCB' ISO line (B1) can be given as:

$$
T C B^{\prime}(B 1)=p-S R \times \lambda
$$

Rearranging (9) gives

$$
p=T C B^{\prime}(B 1)+S R \times \lambda
$$

From (10), the slope of TCB' ISO-line (B1) at point B1 can be obtained as

$$
p^{\prime}\left(S R_{0}\right)=\lambda
$$

Since the straight line TCB' ISO-line (B1) is tangential to the price-rating curve, in principle, the slope of curve $S$ at the tangent point should be equal to the slope of the ISO-line (B1). Applying this rule, the following relationship is obtained:

$$
b+2 c S R_{0}=\lambda
$$

So that,

$$
S R_{0}=\frac{\lambda-b}{2 c}
$$

Substituting this into equation (6) for point b1 gives:

$$
p_{0}=a+\left(\frac{\lambda^{2}-b^{2}}{4 c}\right)
$$

Therefore, equations (13) and (14) form a mathematical optimisation bid model for contractors to calculate their most competitive bidding parameters consisting of: tender price, $\mathrm{p}_{0}$ and sustainability rating, $\mathrm{SR}_{0}$. In this model, it is assumed that $\lambda$ is specified by the client while constants $a, b$ and $c$ determine the shape of the contractor's price-rating curve. Shen et al. (1999) suggest that these constants may be estimated using polynomial regression analysis but at least three pairs of $S R$ and $p$ values are required. The formulation to calculate these constants are given in the Appendix. 


\section{Application of optimisation bid model}

A hypothetical example is used to illustrate the model proposed. Assume that Mudajaya, a contractor company is tendering for a building project. The project client specifies that the sustainability rating value is $\$ 1,000 /$ rating. The contractor's estimating department provides three tenders as follows:

- $\quad$ Tender 1: $S R 1=2, p 1=100,000$

- $\quad$ Tender 2: $S R 2=3, p 2=110,000$

- $\quad$ Tender 3: $S R 3=5, p 3=120,000$.

In order to adopt the most competitive bidding strategy, the contractor needs to determine what tender price and sustainability rating to propose for the building project to produce optimum competitiveness. The optimisation bid model proposed in this paper can be used to guide the contractor in deciding optimal bidding parameters namely the tender price and proposed sustainability rating. From the Appendix, the constants $a, b$ and $c$ can is determined to be:

$$
a=70,000 b=18,333.33 \text { and } c=-1,666.67
$$

Therefore, the price-rating relationship can be given by the following equation:

$$
p=70000+18333.33 S R-1666.67 S R^{2}
$$

By applying the values of these constants and $\lambda=\$ 1,000 /$ rating, the optimal bid price and sustainability rating [see equations (13) and (14)] are calculated as follows:

$$
\begin{aligned}
& S R=\left(\frac{1000-18333.33}{2(-1666.67)}\right)=5 \\
& p=70000+\left(\frac{1000^{2}-(18333.33)^{2}}{4(-1666.67)}\right)=\$ 120,600
\end{aligned}
$$

Therefore, Mudajaya's best competitive strategy is to offer a bid price of $\$ 120,600$ and propose a sustainability rating of 5 for the building project. This would give Mudajaya the highest winnign chance as it gives the lowest $\mathrm{TCB}^{\prime}$ value to the client.

\section{Conclusions}

Traditionally, construction contracts have been awarded on the basis of bid price. However, increasingly more attention is being paid to sustainability attributes of projects. Such a development requires an innovative contracting method which not only considers the bid price but also the sustainability rating of projects. Yet, none of the existing contracting methods incorporates these two parameters (bid price and sustainability rating). The proposed contracting method in this paper is the first to do so (see Figure 7). Sustainability value expressed as SAV has an impact on the client's evaluation of the competiveness of the contractor. 
Figure 7 Flow diagram

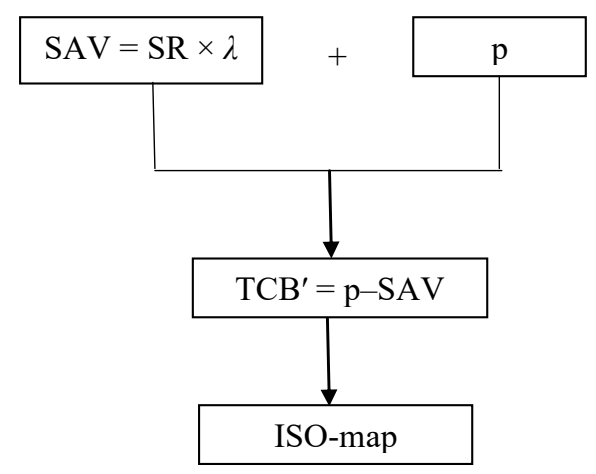

By using the SAV specified by the client, this paper offers contractors a bid optimisation model. The proposed model helps contractors to identify what is the most competitive bidding strategy and can therefore put in a bid with a higher chance of winning. The TCB' ISO-map, on the other hand, provides clients with an alternative approach to evaluate the contractor's competitiveness factoring both bid price and sustainability rating. This would assist the client in identifying the most competitive tender on the map easily.

Future research could explore the effectiveness of this bi-parameter contracting model by applying it on projects of varying scales. There is also a possibility of introducing a tri-parameter model incorporating bid price, construction time and sustainability rating. It is expected that such a model would be more complicated given the number of parameters that are dealt with.

\section{References}

Abudayyeh, O., Zidan, S.J., Yehia, S. and Randolph, D. (2007) 'Hybrid prequalification-based, innovative contracting model using AHP', Journal of Management in Engineering, Vol. 23, No. 2, pp.88-96.

Akintoye, A. (1994) 'Design and build: a survey of construction contractor's views', Construction Management and Economics, Vol. 12, No. 2, pp.155-163.

Akintoye, A., Bowen, P. and Hardcastle, C. (1998) 'Macro-economic leading indicators of construction contract prices', Construction Management and Economics, Vol. 16, No. 2, pp.159-175.

Bayraktar, M., Cui, Q., Hastak, M. and Minkarah, I. (2004) 'State-of-practice of warranty contracting in the United States', Journal of Infrastructure Systems, Vol. 10, No. 2, pp.60-68.

Berends, T.C. (2000) 'Cost plus incentive fee contracting - experiences and structuring', International Journal of Project Management, Vol. 18, No. 3, pp.165-171.

Canadian Construction Documents Committee (CCDC) (1998) Construction Warranties, Ontario [online] http://www.ccdc.org/bulletins/pdf/eng/bulletin17.pdf (accessed 6 April 2015).

Chan, A., Ho, D. and Tam, C. (2001) 'Design and build project success factors: multivariate analysis', Journal of Construction Engineering and Management, Vol. 127, No. 2, pp.93-100.

Chan, E.H.W. and Yu, A.T.W. (2005) 'Contract strategy for design management in the design and build system', International Journal of Project Management, Vol. 23, No. 8, pp.630-639.

Cole, R.J. (1999) 'Building environmental assessment methods: clarifying intentions', Building Research and Information, Vol. 27, Nos. 4-5, pp.230-246. 
Crawley, D. and Aho, I., (1999) 'Building environmental assessment methods: application and development trends', Building Research and Information, Vol. 27, Nos. 4-5, pp.300-308.

Cui, Q. and Zhu, X. (2011) 'Green contracting in highway construction: state of the practice', Journal of the Transportation Research Board, Vol. 2228, pp.11-18.

El-Rayes, K. (2001) 'Optimum planning of highway construction under A+B bidding method', Journal of Construction Engineering and Management, Vol. 127, No. 4, pp.261-269.

Emons, W. (1989) 'The theory of warranty contracts', Journal of Economic Surveys, Vol. 3, No. 1, pp.43-57.

Erevelles, S. (1993) 'The price-warranty contract and product attributes', Journal of Business Research, Vol. 27, No. 2, pp.171-181.

Gordon, C. (1994) 'Choosing appropriate construction contracting method', Journal of Construction Engineering and Management, Vol. 120, No. 1, pp.196-210.

Gransberg, D.D. and Senadheera, S.P. (1999) 'Design-build contract award methods for transportation projects', Journal of Transportation Engineering, Vol. 126, No. 6, pp.565-567.

Green Building Council of Australia (GBCA) (2013) Environmental Benefits of Green Star Buildings Are Too Good To Ignore, Sydney [online] https://www.gbca.org.au/news/gbcamedia-releases/environmental-benefits-of-green-star-buildings-are-too-good-to-ignore/ (accessed 23 March 2015).

Guggemos, A.A. and Horvath, A. (2006) 'Decision-support tool for assessing the environmental effects of constructing commercial buildings', Journal of Architectural Engineering, Vol. 12, No. 4, pp.187-195.

Gupta, D. (2011) Optimal Contract Mechanism Design for Performance-Based Contracts, Minnesota Department of Transportation [online] http://www.lrrb.org/media/reports/ 201118.pdf (accessed 9 August 2016).

Hale, D.R., Shrestha, P.P., Gibson Jr., G.E. and Migliaccio, G.C. (2009) 'Empirical comparison of design/ build and design/bid/build project delivery methods', Journal of Construction Engineering and Management, Vol. 135, No. 7, pp.579-587.

Harrington, J.E., Thum, R.B. and Clark, J.B. (1984) 'The owner's warranty of the plans and specifications for a construction project', Public Contract Law Journal, Vol. 14, No. 2, pp.240-261.

Herbsman, Z.J., Chen, W.T. and Epstein, W.C. (1995) 'Time is money: innovative contracting methods in highway construction', Journal of Construction Engineering and Management, Vol. 121, No. 3, pp.273-281.

Hosseinian, S. and Carmichael, D. (2013) 'Optimal incentive contract with risk-neutral contractor', Journal of Construction Engineering and Management, Vol. 139, No. 8, pp.899-909.

Kibert, C.J. (1994) Establishing Principles and a Model for Sustainable Construction in First International Conference of CIB TG 16 on Sustainable Construction, Tampa, Florida, 6-9 November.

Kwon, H.D., Lippman, S.A. and Tang, C.S. (2010) 'Optimal time-based and cost-based coordinated project contracts with unobservable work rates', International Journal of Production Economics, Vol. 126, No. 2, pp.247-254.

Lambropoulos, S. (2007) 'The use of time and cost utility for construction contract award under European Union legislation', Building and Environment, Vol. 42, No. 1, pp.452-463.

Miller, N., Spivey, J. and Florance, A. (2008) 'Does green pay off?', Journal of Real Estate Portfolio Management, Vol. 14, No. 4, pp.385-400.

Ndekugri, I. and Turner, A. (1994) 'Building procurement by design and build approach', Journal of Construction Engineering and Management, Vol. 120, No. 2, pp.243-256.

Ng, E.L.M. (2013) Impact of Green Buildings on the Value of Property, Master's thesis, Bartlett School of Graduate Studies, University College London, London. 
One Planet Living (2007) Essential Features for a Successful and Sustainable Building, The Green Register of Construction Practitioners [online] http://www.greenregister.org.uk/pro-essential (accessed 18 August 2016).

Palmujoki, A., Parikka-Alhola, K. and Ekroos, A. (2010) 'Green public procurement: analysis on the use of environmental criteria in contracts, review of European', Comparative and International Environmental Law, Vol. 19, No. 2, pp.250-262.

Rosenfield, Y. and Geltner, D. (1991) 'Cost-plus and incentive contracting: some false benefits and inherent drawbacks', Construction Management and Economics, Vol. 9, No. 5, pp.481-490.

Shen, L., Drew, D. and Zhang, Z. (1999) 'Optimal bid model for price-time biparameter construction contracts', Journal of Construction Engineering and Management, Vol. 125, No. 3, pp.204-209.

Siew, R.Y.J. (2014a) Evaluating and Enhancing the Impact of Sustainability Reporting Tools (SRTS), PhD thesis, School of Civil and Environmental Engineering, University of New South Wales (UNSW), Sydney.

Siew, R.Y.J. (2014b) 'A review of sustainability reporting tools (SRTs) for communities', International Journal of Sustainable Construction Engineering and Technology, Vol. 5, No. 2, pp.39-52.

Siew, R.Y.J. (2015) 'Alternative framework for assessing sustainable building funds: green building fund', Building Research and Information, Vol. 43, No. 2, pp.160-169.

Siew, R.Y.J., Balatbat, M.C.A. and Carmichael, D.G. (2013) 'A review of building/infrastructure sustainability reporting tools (SRTs)', Smart and Sustainable Built Environment, Vol. 2, No. 2, pp.106-139.

Singh, P., Oh, J., Labi, S. and Sinha, K. (2007) 'Cost-effectiveness evaluation of warranty pavement projects', Journal of Construction Engineering and Management, Vol. 133, No. 3 , pp.217-224.

Songer, A.D. and Molenaar, K.R. (1996) 'Selecting design-build: public and private sector owner attitudes', Journal of Management in Engineering, Vol. 12, No. 6, pp.47-53.

Thompson, B., Anderson, S., Russell, J. and Hanna, A. (2002) 'Guidelines for warranty contracting for highway construction', Journal of Management in Engineering, Vol. 18, No. 3, pp.129-137.

USGBC (2014) Top 10 Ways to Use Recovery Funds for Green Building, USGBC, US [online] http://www.fundinggreenbuildingscom/documents/Top10waysToGreenWithStimulusFunds.pd f (accessed 4 April 2015).

Varnäs, A., Balfors, B. and Faith-EII, C. (2009) 'Environmental consideration in procurement of construction contracts: current practice, problems and opportunities in green procurement in the Swedish construction industry', Journal of Cleaner Production, Vol. 17, No. 13, pp.1214-1222.

\section{Appendix}

Polynomial regression analysis suggests that values for constants $a, b$ and $c$ is calculated from the following (Shen et al., 1999):

$$
\begin{aligned}
& n a+b \sum S R_{i}+c \sum S R_{i}^{2}=\sum p_{i} \\
& a \sum S R_{i}+b \sum S R_{i}{ }^{2}+c \sum S R_{i}^{3}=\sum S R_{i} p_{i} \\
& a \sum S R_{i}^{2}+b \sum S R_{i}^{3}+c \sum S R_{i}^{4}=\sum S R_{i}{ }^{2} p_{i}
\end{aligned}
$$

where $n=$ number of pair values, the other variables remain the same as described in the paper. 